\title{
Resilience in the built environment: How to evaluate the impacts of flood resilient building technologies?
}

\author{
Sebastian Golz ${ }^{1, a}$ \\ ${ }^{1}$ Leibniz-Institute of Ecologic Urban and Regional Development, Weberplatz 1, 01217 Dresden, Germany
}

\begin{abstract}
The EU floods directive and its transcription into national legislation request exposed citizens and organisations to take individual measures to reduce flood risks on building scale. In response to that issue, a number of general approaches to buildings in flood risk areas and a set of strategies and technical guidance for the design and construction of flood resilient buildings have been developed in recent years. Particularly flood resilient building materials and constructions (FReMaCo), e.g. adapted exterior wall systems or floor arrangements, are expected to provide a considerable potential to limit flood damage if, for example, aperture technologies cannot stop water entering the building. However, there are significant uncertainties about the performance of FReMaCo that impede their comparison and hamper their uptake. To reduce those obstacles the paper discusses the application of the analytic hierarchy process (AHP) (i) to quantify and to compare the physical flood vulnerability of various building constructions and (ii) to evaluate and to rank the impact of alternative FReMaCo options. The paper explores a set of eleven evaluation criteria ranging from statics criteria about buildings physics criteria up to durability criteria. The AHP generates a weight for each defined criterion and assigns a score for each FReMaCo option. Then, the AHP combines the criteria weights and the option scores to determine a global score for each construction alternative that evaluate the impact of FReMaCo options in a comprehensible manner. The application of AHP reduces the bias in the decision making process and is therefore of international interest, especially for those involved in improving the resilience properties of buildings.
\end{abstract}

\section{Introduction}

The impacts of floods on housing are increasing due to more frequent and severe weather events as well as the ongoing development of settlements in flood-prone areas together with the rising vulnerability of assets at risk. The European Union floods directive (Commission directive $2007 / 60 / E C$ ) and its transcription into national legislation reinforce a holistic framework for the assessment and management of flood risks and request exposed citizens and organisations to take individual measures to reduce adverse consequences at the receptor scale (European Union 2007).

In response to that issue, a range of general approaches to buildings and their components has already been developed in recent years. Many of these approaches provide general strategies, namely, 'avoidance', 'dryproofing' and 'wet-proofing' as well as generic concepts for both the design and construction of new houses and the adaptation of existing buildings in flood risk areas (e.g. Bowker 2007, Naumann et al. 2010, FEMA 2010). Nevertheless, most of these approaches do not explore comprehensively the potential of physical measures, i.e. direct structural interventions into buildings at risk, to reduce flood damage because there is only little relevant evidence of research on how they improve flood resilience.

Golz et al. (2015) state that the concept of resilience is widely used in different scientific disciplines. However, the meaning of resilience often remains inexplicit as the term is used ambiguously and in a very wide extension. With respect to the built environment, Naumann et al. (2011), Lawson (2011) and Garvin (2012) define flood resilience as the ability of buildings to recover easily and quickly from damaging effects, i.e. the authors emphasize particularly the speed of recovery. Therefore, the enhancement of the flood resilience properties of built structures is generally aimed at minimising flood impacts, i.e. to decrease direct and indirect tangible flood damage (e.g. Merz et al. 2010).

In the last two decades, a growing market has been emerging for technologies that support various flood damage mitigation efforts. Lawson (2011) specify these technologies as any method, product or material that help to manage flood risk at individual building level. Research in the collaborative European SMARTeST project compiled a remarkable catalogue of available flood resili-

\footnotetext{
$\overline{{ }^{a} \text { Corresponding author: s.golz@,ioer.de }}$
} 
ent technologies (FReT) based on an international survey (Gabalda et al. 2013). Connelly et al. (2015) and Golz et al. (2015) propose a categorisation of available FReT according to their application:

- Perimeter technologies grouped into pre-installed, demountable and temporary perimeter flood barriers

- Building aperture technologies grouped into preinstalled, demountable or temporary building aperture barriers

- Building technologies grouped into flood resilient building products (e.g. flood resilient equipment) and flood resilient building materials and constructions

White et al. (2013) explored the obstacles and reluctance to implement FReT. It became obvious that the acceptance of FReT implementation is compromised particularly by an inadequate transparency of their expected performance upon which to base decisions. Consequently, a key criterion for the implementation of FReT is having sufficient evidence about their specific level of performance. According to Samuels and Gouldby (2009), performance can be understood as the degree to which a process or activity succeeds when evaluated against some stated aim or objective. Within this context, the performance of FReT is indicated by their effectiveness and reliability (Golz et al. 2015). Other approaches cover additional indicators such as sustainability, tolerability, robustness or flexibility. Effectiveness describes the extent to which the objectives of an intervention are achieved (OECD 2002). Reliability of physical measures indicates the probability of failure and depends on the construction of a measure. The evaluation of the efficiency that generally relates the achieved positive effects (benefits) to the used resources (expenditures, costs) of FReT implementation in monetary terms is not within the scope of this paper.

On an individual building scale the set of flood resilient technologies comprises, first, building aperture technologies for the temporary watertight closure of façade openings such as doors, windows or ventilation elements and, second, building technologies that address either flood resilient building products or flood resilient building materials and constructions.

Flood resilient building products embrace (i) materials or systems for the permanent sealing of the building envelope such as membranes or hydrophobic impregnations, (ii) anticorrosive coatings that prevent triggering destructive processes as well as (iii) smart domestic flood warning systems that operate flood barriers automatically. In general, the implementation of building aperture technologies and flood resilient building products intends to keep floodwater outside the building up to a defined design level. It is obvious that an effective dry proofing strategy requires a holistic approach, because the implementation of single building aperture technologies or flood resilient building products are often not sufficient to block each potential water entry route into the building. Furthermore, it is apparent that this dry proofing strategy is limited by the individual strength of the particular external wall constructions to withstand flood actions e.g. hydrostatic pressure without structural failure.

In contrast, flood resilient building materials and constructions (FReMaCo) are related to the wet proofing strategy. Notwithstanding, building aperture technologies and flood resilient building products are available on the market, which can help to stop floodwater entering the building, there can nevertheless be a significant risk that building assemblies in flood-prone areas have to cope with floodwater, e.g. due to overtopping or failure of flood defences. Hence, FReMaCo provide advice on how to design new or how to modify existing building assemblies, e.g. use of adequate external wall or floor constructions, in order to minimise the extent of necessary repair works in case of floodwater has entered the building.

The recommendation of FReMaCo considers material interrelations in composite building constructions as well as their structural integrity and inherent resilient characteristics. Laboratory tests, determining the resilience properties of building assemblies, have also been conducted e.g. by Gamerith and Hoefler (2006), Bowker et al. (2007), Escarameia et al. (2007), Gabalda et al. (2012), Garvin et al. (2012), and Golz (forthcoming). However, there are no regulations available for FReMaCo at national or European level, despite the increased endorsement of resilience in flood risk management (e.g. Escarameia et al. 2012, Golz 2016).

Particularly the exploration of resilient building engineering design through the implementation of innovative FReMaCo is expected to provide a previously widely underestimated potential to reduce flood damage, but there is insufficient clarity and a significant uncertainty about the quantity of their performance (Escarameia et al. 2007, Golz et al. 2013). Therefore, this paper concentrates on FReMaCo that are incorporated into the design of new and existing buildings to ensure flood damage mitigation.

Of particular relevance to the implementation of FReMaCo is not only the knowledge of precise data regarding site-specific flood hazard but also the awareness about the physical vulnerability of a building. While flood hazard maps and flood risk maps at high spatial resolution are presently available for the majority of European river basin districts, the physical flood vulnerability of conventional building materials and constructions is almost unknown or discussed controversially, e.g. due to the complexity of damage mechanism. The physical vulnerability is the intrinsic fragility due to hazardous flood events that can be generally specified by the degree of experienced harm of their materials and structures, i.e. by the propensity to suffer damage (e.g. Douglas 2007, Blanco and Schanze 2014).

Against this background, this paper asks (i) how to quantify and to compare the physical flood vulnerability of various building constructions to achieve a comprehensive understanding of negative flood consequences and (ii) how to evaluate and to rank the performance of alternative FReMaCo options in order to facilitate their uptake by architects, engineers and other involved professional stakeholders. 


\section{Methodological Framework}

A multi-stage approach that links different methods with each other serves to answer the both research questions. This approach incorporate methods

- for analysing the moisture behaviour of various building constructions (e.g. multi-layer wall constructions) that have to cope with flooding,

- for evaluating the physical vulnerability due to flooding and

- for the derivation of guidance for the implementation of FReMaCo to reduce flood risk.

Basically, the moisture behaviour of building materials and constructions can be examined quantitatively by means of empirical laboratory studies or numerical simulation procedures. Both processes enable the analysis e.g. of time-varying water absorption and water transport procedures in multi-layer wall arrangements. However, no normative regulations exist to date as specified by a standardised test process, with whose aid the moisture conditions occurring in affected construction components concerned can be re-adjusted and evaluated.

Based on the investigations related to the moisture behaviour, specific criteria for the determination and evaluation of the physical flood vulnerability of existing building constructions are identified. The central focus is initially on the analysis of the interdependencies between the documented moisture behaviour and the negative consequences.

These analyses serve for the development of relevant evaluation criteria. The multi-criteria evaluation enables the systematic comparison and ranking of building constructions concerning their physical flood vulnerability. The requirements on multi-criteria-related evaluation procedures are (among other things) that they must enable the evaluation of construction alternatives on a single cardinal scale. For this, the Analytical-Hierarchical Process (AHP) is employed.

On the basis of these evaluations, handling options of the physical provision against risks can be derived consistently and transparently, which, with regard to the objectives to be pursued, represent an effective (optimal) construction design solution. By means of the methodical approach employed, the effects of various different building-constructive measures can thus be estimated, with reference to the decrease of the risk.

\subsection{Method for analysing the moisture behaviour}

The moisture behaviour of multi-layer building constructions can be predicted approximately with different models. Frequently, however, the complexity of real system procedures cannot be represented in the level of detail resolution desired. The development of a conceptional model enables the description of the elements exclusively relevant for the respective investigation objective, as well as their mutual relations with respect to each other and with the environment. For this, the physical reality is abstracted and idealised to the necessary degree. This conceptional model forms the basis both for mathematical as well as for experimental models. These in turn act as a necessary basis for simulations and/or experiments. Very high requirements are made on the majority of models employed in the building trade in general on the load carrying capacity and reliability of their results.

\subsection{Multi-criteria evaluation method}

The AHP according to Saaty (1980) is a reliable and theoretically well-founded process, which compensate the often criticised weaknesses of the utility value analysis, in particular the subjectivity of the weighting. The application of the AHP has the objective to determine the relative importance of eleven evaluating criteria. The algorithm is associated with the hierarchically additive weighting processes and makes possible the arrangement of different alternatives, as well as the specification of the best alternative according to the maximum principle.

\begin{tabular}{|c|l|l|}
\hline $\begin{array}{c}\text { Intensity of } \\
\text { importance }\end{array}$ & Definition & Explanation \\
\hline \hline 1 & $\begin{array}{l}\text { Equal } \\
\text { importance }\end{array}$ & $\begin{array}{l}\text { Two elements contributes } \\
\text { equally to the objective }\end{array}$ \\
\hline 3 & $\begin{array}{l}\text { Moderate } \\
\text { importance }\end{array}$ & $\begin{array}{l}\text { Experience and judgement } \\
\text { slightly favour one ele- } \\
\text { ment over another }\end{array}$ \\
\hline 5 & $\begin{array}{l}\text { Strong } \\
\text { importance }\end{array}$ & $\begin{array}{l}\text { Experience and judgement } \\
\text { strongly favour one ele- } \\
\text { ment over another }\end{array}$ \\
\hline 9 & $\begin{array}{l}\text { Very strong } \\
\text { importance }\end{array}$ & $\begin{array}{l}\text { One element is favoured } \\
\text { very strongly over another; } \\
\text { its dominance is demon- } \\
\text { strated in practice }\end{array}$ \\
\hline $2,4,6,8$ & Intermediate values & $\begin{array}{l}\text { The evidence favouring } \\
\text { one element over another } \\
\text { is of the highest possible } \\
\text { order od affirmation }\end{array}$ \\
\hline
\end{tabular}

Table 1. Fundamental scale for pairwise comparison following

Poschmann et al. (1998) cited in Bloech und Götze (2004).

The AHP is characterised (among other things) by the fact that the criteria which appear evaluation-relevant are selected and classified according to their relevancy. The 9-point scale represented in Table 1 serves for this. The stipulation of the weighting values for the criteria to be included forms an elementary step in the algorithm of the evaluation procedure. The weighting coefficients cannot be determined objectively in the majority of cases, rather they reflect the implicit preferences of the respective decision-maker only. The AHP process formalises the set-up of a hierarchical targeting system, the weighting of the criteria and the evaluation of the alternatives with regard to every criterion.

The special feature of the AHP basically consists in the special systematic procedural method, where the criteria are always compared pairwise with each other. During the ongoing process, it must be assessed how the 
importance of one criterion with respect to another criterion is estimated. For every criteria pair it can be determined which criterion is more important and how great the difference in importance is. Corresponding to Table 1, the difference is to be evaluated on a scale of 1 (equivalent) to 9 (maximum difference in importance). In case of $n$ criteria

$$
n b_{\text {comp }}=\frac{n *(n-1)}{2}
$$

comparisons are to be implemented. The results of all pairwise comparisons lead to an evaluation matrix $\boldsymbol{A}$

$$
\boldsymbol{A}=\left[\begin{array}{ccc}
a_{1,1} & \cdots & a_{1, n} \\
\vdots & \ddots & \vdots \\
a_{n, 1} & \cdots & a_{n, n}
\end{array}\right]
$$

from which the weighting values for $n$ criteria can be calculated. The matrix elements $a_{i, j}$ follow the formation specification:

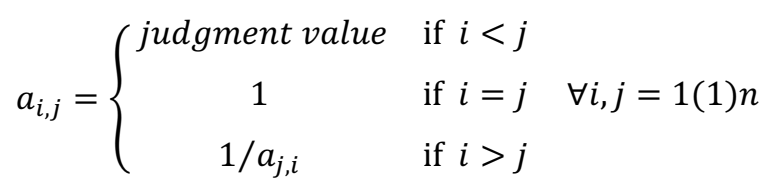

After the calculation of the column sums $S_{j}$ of the matrix $\boldsymbol{A}$

$$
S_{j}=\sum_{i=1}^{n} a_{i, j} \quad \forall j=1(1) \mathrm{n}
$$

and the standardisation of the elements of the matrix $\boldsymbol{A}$

$$
b_{i, j}=\frac{a_{i, j}}{s_{j}} \quad \forall i, j=1(1) \mathrm{n}
$$

the determination of the relative weighting values $w_{i}$ of the criteria is implemented:

$$
w_{i}=\frac{\sum_{j=1}^{n} b_{i, j}}{n} \quad \forall i=1(1) \mathrm{n}
$$

This procedure represents an advantage with respect to the utility value analysis, since it bypasses a random stipulation of the weighting values. The decision-maker is compelled to examine his targets in detail. It is striven to combine these elements of the AHP with the utility value process. It is to be considered that, with the process, the order of priority of the alternatives can change as a result of the insertion or removal of an alternative. The result therefore has meaning only within the framework of the alternatives considered and does not represent any absolute value for use.

Following equations 2 to 5 , the respective weightings of the criteria over the eigenvector of the matrix $\boldsymbol{A}$ are calculated with the largest eigenvalue. In order to identify inconsistencies in the weighting, the Consistency Index $C I$ and the Consistency Ratio $C R$ are determined.

$$
\lambda_{i}=\frac{A w_{i}}{w_{i}} \quad \forall i=1(1) \mathrm{n}
$$

with

$$
A w_{i}=\sum_{j=1}^{n} a_{i, j} w_{j} \quad \forall i=1(1) \mathrm{n}
$$

The Consistency Index $C I$ results from the number of indicators $n$ and the average value of the eigenvalues $\bar{\lambda}$

$$
\bar{\lambda}=\frac{\sum_{i=1}^{n} \lambda_{i}}{n}
$$

to

$$
C I=\frac{\bar{\lambda}-n}{n-1}
$$

The Consistency Ratio $C R$ is defined as a quotient of the Consistency Index $C I$ and the Random Index $R I$ :

$$
C R=\frac{C I}{R I}
$$

The Random Index RI serves as a comparison dimension and is dependent on the number of criteria $n$, that is on the matrix arrangement. Saaty (2000) includes the average random index for reciprocal coincidence matrices with $n$ lines. The pairwise comparisons are consistent when the condition $C R<0,1$ is verified. Otherwise, the pair comparisons are to be adapted for so long until the consistency condition is fulfilled.

\section{Subject of investigation}

\subsection{Delimitation}

During flood event, particularly the building envelope that separates the building against the environment is exposed intensively to pressing water issues. External wall constructions of different design type as well as windows and external doors with their respective connection constructions are included among these exposed elements in particular. Traditional exterior wall constructions can be differentiated, based on the construction materials mainly employed, into the following design types:

- Brickwork constructions

- Wooden support and timber panel constructions

- Reinforced concrete constructions

- Steel-glass constructions

Windows and doors, with their respective connections to the surrounded building, are potential weak points in the building envelope, as well as joints, penetration passages and transitions in particular, which consequently require a detailed specialist consideration in this connection.

Brickwork constructions from artificial, industriallymanufactured bricks, for example bricks or other minerallinked blocks, such as calcareous sandstone, aerated con- 
crete or light-weight concrete, have been dominating construction design for decades in external wall construction in house building, due to their favourable static and building-physical characteristics.

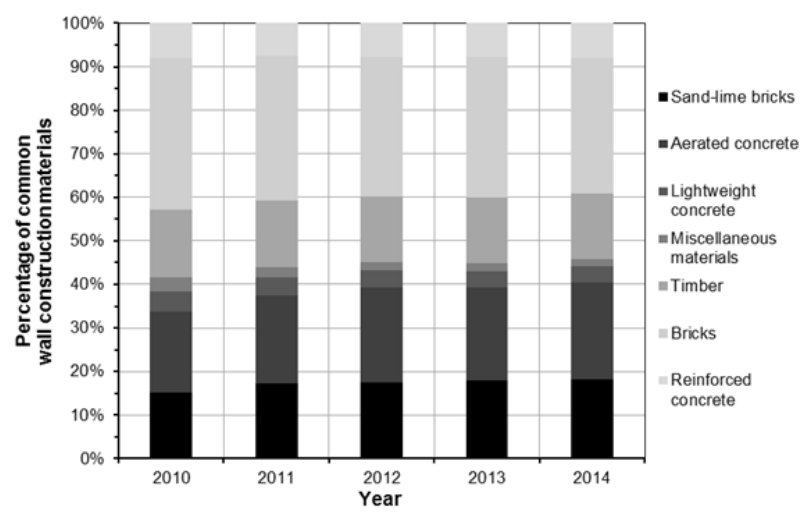

Figure 1. Percentage of usual wall construction materials in building permits for the new construction of residential buildings in Germany between 2010 and 2014. Source: Federal Statistical Office.

A survey of building permits, issued in Germany since 1997 for the new construction of residential buildings, differentiates the predominantly applied materials for exterior wall constructions. The results clarify the high percentage (about two thirds) of bricks and other blocks in the implementation of residential buildings during the past 19 years. For the years 2010 to 2014, the German Federal Office of Statistics has released additionally acquired data, which allows an even more detailed analysis of the allocation of construction materials mainly employed in new building projects (see bar chart in Figure 1). The dominating market share, and therefore the assumed widespread spatial distribution of masonry constructions, legitimises an in-depth analysis of their physical flood vulnerability.

Constantly increasing demands in particular are associated with the most important leitmotifs for new and ongoing technical developments in brickwork construction in past decades with regard to

- the use of rationalisation potentials,

- the optimisation of thermal insulation, acoustic insulation and fire protection characteristics,

- the guarantee of protection against moisture and wind-driven rain,

- the increase in importance of ecological aspects, such as primary energy content and greenhouse potential, as well as

- the increase of implementation security.

These diverse requirements determine the implementation in multiple-layer, sometimes also multiple-shell, brickwork constructions (Figure 2). In particular the increased normative requirements on the heat insulation of opaque component parts lead (among other things)

- to the rapid expansion of whole-brick masonry with large-format concrete precision blocks and plan elements, in association with light-weight mortar in thin mortar bedding, in order to reduce the influence of ir- regularities with regard to the thermal conductivity of the brickwork,

- to the reduction of the wall-brick bulk density by increasing the pore volume in the material grain structure (for example through brick fragments made porous), as well as the empty-space content with stationary air (hole content in the brick), as well as

- to the ex-works integration of thermal-insulating materials, such as pearlites or fibre insulation materials bonded with synthetic resin, into the stone perforations, in order to limit the specific transmission-heat losses through the opaque external wall cross-section.

However, it is presumed that the premises of both new and ongoing developments in brickwork construction conflict with the physical flood vulnerability. To what extent this correlation can be established concerning that is indicated by the evaluation of the results in this article.

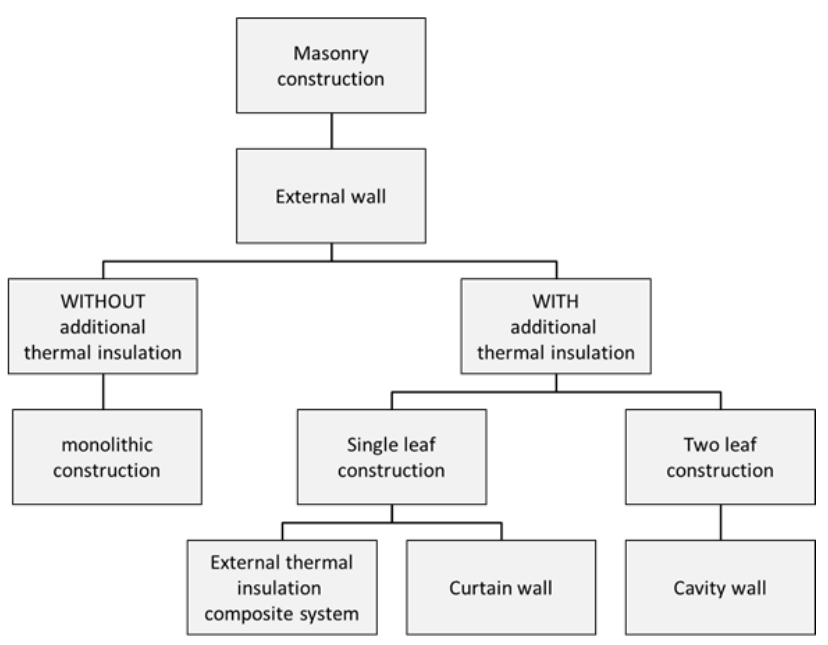

Figure 2. System overview of exterior masonry constructions.

\subsection{Typical wall cross-sections}

The majority of masonry constructions is generally technologically easy to produce. The wall bond, with its two shape-providing components of brick and bedding mortar, forms a defined geometrical system, independent of the respective material of the wall formation. The following section describes and visualises the constructive formation of the eight non-reinforced wall crosssections examined. It is to be noted that all building products employed are controlled by standards or are provided with a general construction-supervision certification, which verifies their respective usability.

The selection of the subject of investigation is based on the necessity to represent the bandwidth of usual brickwork construction designs, which are frequently implemented in the residential building inventory and are widespread. The residential building typology extends from the isolated single-family house, through the terraced house, up to the multi-family house in closed block edge development. 
The upper row in Figure 3 therefore indicates singleshell, monolithic brickwork construction designs without additional external thermal insulation:

- EMW-MZ: Single-shell brickwork of traditional, small-format solid bricks

- EMW-HLz: Single-shell brickwork of light vertically perforated bricks

- EMW-PP: Single-shell brickwork of aerated concrete level blocks

- EMW-PziWD: Single-shell brickwork of level vertically-perforated bricks with integrated thermal insulation

The display series below includes single-shell and multiple-shell brickwork constructions which, however, are provided with an additional, external, thermalinsulation layer in order to meet the requirements on structural heat insulation, for instance:

- EMW-Hbl_WDVS: Single-shell brickwork of lightweight, concrete hollow blocks with additional external thermal insulation

- EMW-HLz_WDVS: Single-shell brickwork of vertically perforated bricks, with additional external thermal insulation

- EMW-HLz_VHF: Single-shell brickwork of vertically perforated bricks, with additional, external thermal insulation and rear-ventilated external wall panelling

- ZMW-KS_WZ: Double-shell exposed masonry of calcareous sandstone with core insulation

\section{Evaluating the physical vulnerability}

This article deals operationally with the evaluation of the susceptibility to damage of alternative brickwork constructions with respect to flooding, in order to differentiate transparently and understandably between disadvantageous and advantageous construction-design solu- tions. In what follows, construction alternatives can be placed into an order of priority (preference relation) with regard to their suitability for floodwater stressing. From the evaluation of the sum of these criteria, (i) the damage susceptibility of the non-adapted constructions, as well as (ii) the effectiveness and (iii) efficiency of buildingconstructive options for the reduction of the damage susceptibility, are determined with the aid of a suitable method set.

The development and implementation of FReBT are oriented to the evaluation results of the non-adapted constructions, which identify the decisive deficits and thus support the derivation of solutions. The repeated implementation of the evaluation algorithm, however this time considering the designed adaptation measures, allows the estimation of the effectiveness of the selected structuralengineering options, which characterise the quantity of their effects in comparison with the targeted values.

The AHP is included among the processes, which enable a comprehensive and systematic evaluation of different qualitative and quantitative criteria. An evaluation of the damage susceptibility, however, is possible only with reference to values and objectives. Therefore, generally-recognised regulations of the technology, on the one hand, as well as specialist standards from technical regulatory work, such as for example DIN-standards, on the other hand, are used, however, also research results from engineering sciences. In this way, the general legitimacy and relevance in practice of the evaluation should be guaranteed.

\subsection{Criteria selection}

There are various criteria to show the physical flood vulnerability of exterior wall constructions and the performance of FReMaCo concerning vulnerability mitiga-

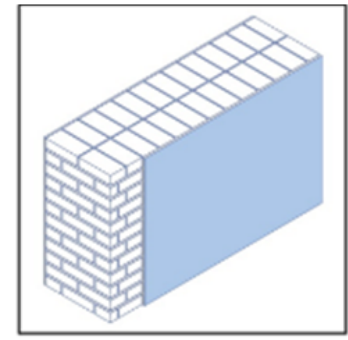

EMW-Mz

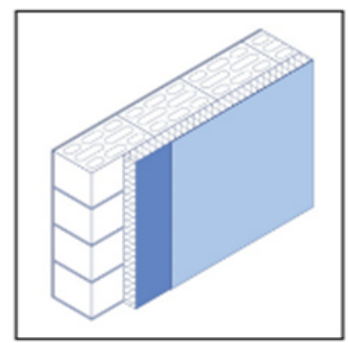

EMW-HbI_WDVS

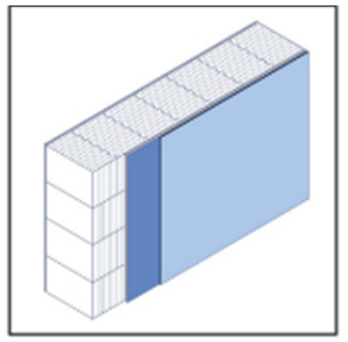

EMW-HL2

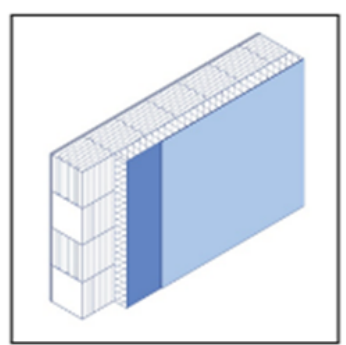

EMW-HLZ_WDVS

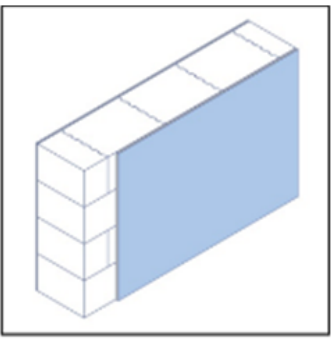

EMW-PP

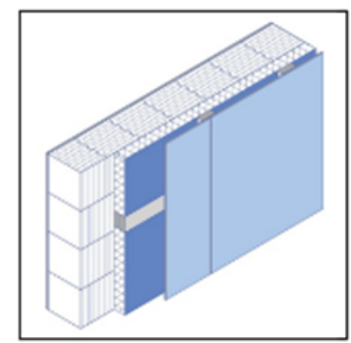

EMW-HL__VHF

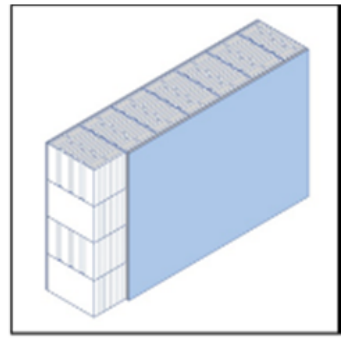

EMW-PZiWD

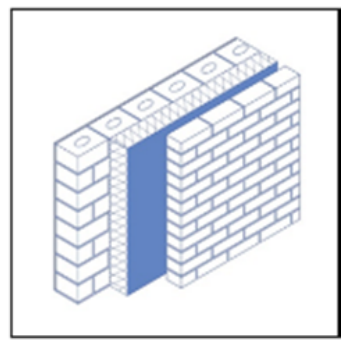

ZMW-KS_WZ

Figure 3. Subject of investigation: Selection of typical external wall constructions of existing buildings. 
tion. The AHP enables a comprehensive and systematic evaluation of different qualitative and quantitative criteria. However, an evaluation of the physical flood vulnerability is possible only with reference to values and objectives. Therefore, generally recognised regulations and codes of technology as well as norms, standards and technical rules from technical regulatory work are used. Moreover, research results from engineering sciences serve . In this way, the general legitimacy and relevance in practice of the evaluation should be guaranteed.

The analysis and evaluation of the physical vulnerability with the aid of the AHP are based on the following four hierarchically-subordinate sub-objectives:

- Retention of the static-constructive integrity

- Resistance of building-physical characteristics

- Suitability of the construction design

- Permanence of the component part, i.e. resistance with respect to biological and chemical corrosion processes

These four sub-objectives are featured by suitable, clearly formulated, more-detailed criteria. Figure 4 includes a taxonomy, which assigns the criteria to be considered to each of the four sub-objectives. The development of the criteria for the evaluation of the constructiondesign solutions is based both on their content-related relevancy and the data availability, as well as on their methodical handling capability. Basically, criteria can be differentiated whose values can be either described qualitatively or defined quantitatively, i.e. measurable. A qualitative criterion is the disassembly capability of the parts of a building component after a flood event.

The effects of this criterion with respect to the subgoal are not directly measurable, rather can be interpreted only on the basis of existing knowledge. A quantitative criterion is the moisture-dependent change of the transverse tensile strength of construction materials. Here a functional connection (utility model) is producible between moisture content and the temporary or permanent property changes.

Minimum requirements apply for certain criteria, such as for example, the change of the compressive strength of statically-relevant, building-component layers. Their failure to fulfil or the undershooting of these criteria is not acceptable, and can therefore lead to the exclusion of a variant from any further evaluation procedure. A thusdesignated utility function (indicator) is assigned to every quantitative criterion. Indicators consequently make possible the objectively-understandable measurement as to how well a criterion fulfils the objective linked with it. Basically, several indicators can exist for every criterion. Every indicator can be addressed as suitable if it is formulated clearly and is operation-capable.

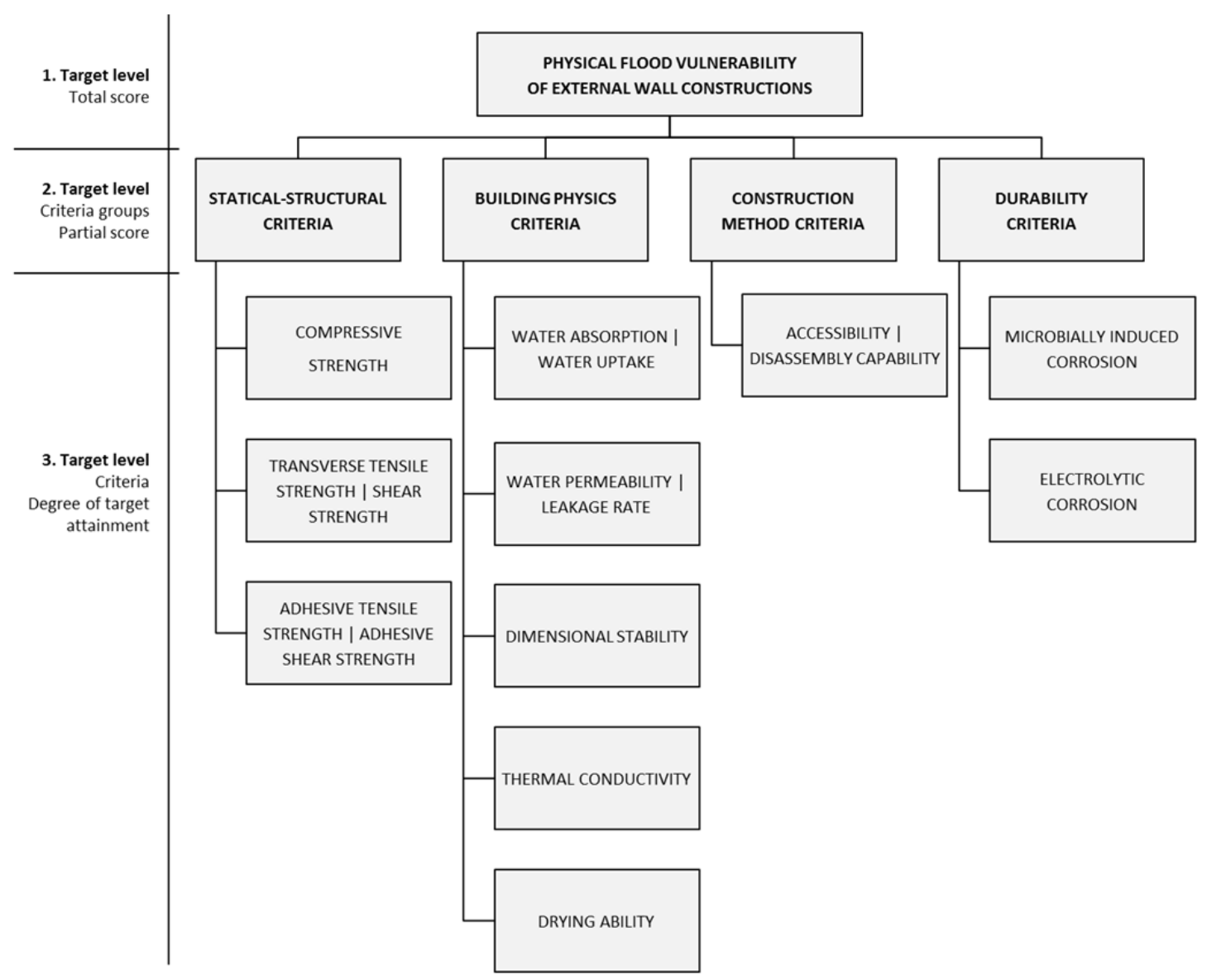

Figure 4. Multi-criteria taxonomy for the physical flood vulnerability evaluation of construction alternatives (criteria hierarchy). 
Table 2. Specification of criteria for the evaluation of the physical vulnerability of brickwork constructions subjected to flooding.

\begin{tabular}{|c|c|c|}
\hline Criterion & Acronym & Specification \\
\hline $\begin{array}{l}\text { Compressive } \\
\text { strength }\end{array}$ & DrFe & $\begin{array}{l}\text { The criterion describes the change of the compressive strength of moisture-stressed construction } \\
\text { materials. The increase of the strength is a positive consequence (chance), a reduction is a negative } \\
\text { consequence (risk). With the evaluation of the criterion, two states are differentiated: (i) the me- } \\
\text { chanical properties of the moist construction material, which can vary depending on the water con- } \\
\text { tent, as well as (ii) the mechanical properties of the re-dried construction material for the moisture } \\
\text { content equilibrium. Based on two different indicators, the criterion considers both reversible and } \\
\text { irreversible strength changes, which can influence the characteristic values of the entire component } \\
\text { part. }\end{array}$ \\
\hline $\begin{array}{l}\text { Transverse } \\
\text { tensile strength | } \\
\text { shear strength }\end{array}$ & QzFe & $\begin{array}{l}\text { The criterion identifies the tendency of construction materials to change their transverse tensile } \\
\text { strength with intensive moisture stressing. The transverse tensile strength in accordance with the } \\
\text { German standard DIN EN } 1607 \text { (thermal insulation materials for the building trade; determination } \\
\text { of the vertical tensile strength to the plate level), which is designated there as tensile strength verti- } \\
\text { cal to the plate level, represents a material property determined under defined test conditions. If } \\
\text { tensile stresses occurring exceed the characteristic strength value, the failure mechanism is desig- } \\
\text { nated as a cohesion break. Two quotients act as indicators for the characterisation of the transverse } \\
\text { list stimuli for that. Building on the experimental study for moisture behaviour, according to the } \\
\text { cond research question, specific methods and criteria for the determination and evaluation of the } \\
\text { e sus }\end{array}$ \\
\hline $\begin{array}{l}\text { Adhesive } \\
\text { tensile strength | } \\
\text { adhesive shear } \\
\text { strength }\end{array}$ & $\mathrm{HzFe}$ & $\begin{array}{l}\text { The criterion characterises the tendency of jointed construction dividers to change their adhesive } \\
\text { tensile strength with intensive moisture stressing. The adhesive tensile strength (also tear strength or } \\
\text { bond strength) is to be understood as tensile strength of certain bonds under construction-practical } \\
\text { conditions. The damage mechanism in connection with the adhesive tensile strength (for example } \\
\text { the peeling of wall linings such as in case of plaster or heat insulation composite systems) is desig- } \\
\text { nated as adhesion failures (failure of the adhesion in the compound joint). Adhesion failure identi- } \\
\text { fies for example the detachment of the adhesion, while the previously described cohesion failures } \\
\text { identifies the overload of the adhering-layer or the bonded parts themselves. Analogous to the } \\
\text { transverse tensile strength, two quotients serve as indicators for the determination of the influence } \\
\text { of increased moisture contents on the characteristic values of the construction. The indicators con- } \\
\text { sider both reversible and irreversible strength changes which can influence the characteristic values } \\
\text { of the entire component part. }\end{array}$ \\
\hline $\begin{array}{l}\text { Water absorption } \\
\text { characteristic }\end{array}$ & WaAuf & $\begin{array}{l}\text { The criterion describes how much water a construction material can absorb into its grain structure } \\
\text { over the wetted surface per unit of time. The material-specific water absorption coefficient acts as } \\
\text { an indicator for the quantification of the capillary suction capability } A_{W} \text {. Therefore, the } A_{W} \text { value } \\
\text { represents the absorption rate of liquid water through the construction material. Plagge et al. (2005) } \\
\text { define the } A_{W} \text { value as an initial rise in the cumulative water absorption curve. In case of materials } \\
\text { with constant pore structure, the capillary water absorption is generally implemented linearly with } \\
\text { the square root of the time. }\end{array}$ \\
\hline $\begin{array}{l}\text { Water } \\
\text { permeability }\end{array}$ & $\mathrm{WaDu}$ & $\begin{array}{l}\text { The criterion evaluates the liquid water volume that reaches the inner side of the construction } \\
\text { through the layer sequences, within a defined time period, in case of brickwork constructions sub- } \\
\text { jected to outside high water. The criterion thus represents the sealing of the construction with re- } \\
\text { spect to penetrating high water. It depends decisively on the pressure gradient, which is influenced } \\
\text { in turn by the water level difference between outer and inner side. }\end{array}$ \\
\hline $\begin{array}{l}\text { Dimensional } \\
\text { stability }\end{array}$ & DiSta & $\begin{array}{l}\text { The criterion identifies the tendency of construction materials to modify their length and/or their } \\
\text { volume dependent on their moisture content (swelling and shrinking). The deformation characteris- } \\
\text { tic is determined from the content of swelling-capable component parts in the construction-material } \\
\text { grain structure and from the moisture range (hygroscopic, over-hygroscopic). The majority of con- } \\
\text { struction materials indicate a reversible swelling and shrinking due to changing water content. The } \\
\text { moisture expansion characteristics of many construction materials is directional. On boundary sur- } \\
\text { faces of jointed materials shearing stresses can arise which lead to the detachment of layers. The } \\
\text { hygroscopic expansion can be represented as a material-specific function of the material moisture. } \\
\text { In case of uneven distribution of the water content in the cross-section, component parts tend to } \\
\text { hygroscopic bending which can lead to bending stresses and to crack formation in case of hindered } \\
\text { deformation. }\end{array}$ \\
\hline $\begin{array}{l}\text { Thermal } \\
\text { conductivity }\end{array}$ & WL & $\begin{array}{l}\text { The thermal conductivity of usual construction materials increases with increasing moisture content. } \\
\text { A positive linear correlation generally exists between the two parameters. The negative energy- } \\
\text { related consequences are increased transmission heat losses by the component part affected. The } \\
\text { indicator characterises this functional connection. The influence of the water content on the insula- } \\
\text { tion properties can be computed, if there are reliable hygrothermal material characteristic values } \\
\text { available. The calculation of the heat transfer, i.e. the heat conduction depending on the water con- } \\
\text { tent, is based on an algorithm that is described e.g. in the German standard DIN EN 15026. It should } \\
\text { be noted that the latent heat transport due to vapour diffusion with phase transition remains uncon- } \\
\text { sidered here. }\end{array}$ \\
\hline
\end{tabular}




\begin{tabular}{|c|c|c|}
\hline Criterion & Acronym & Specification \\
\hline $\begin{array}{l}\text { Drying character- } \\
\text { istics }\end{array}$ & TrVer & $\begin{array}{l}\text { The criterion refers with first priority to the rate with which a construction material can emit accu- } \\
\text { mulated moisture again to the environment. The diffusion resistance number } \mu \text { and the diffusion- } \\
\text { equivalent air layer thickness } s_{d} \text {, as well as the water absorption coefficient } A_{W} \text {, form building- } \\
\text { physical standard characteristic values for the characterisation of the moisture behaviour of con- } \\
\text { struction materials, where the two first-designated parameters identify the drying characteristic due } \\
\text { to diffusion }\end{array}$ \\
\hline $\begin{array}{l}\text { Accessibility | } \\
\text { disassembly capa- } \\
\text { bility }\end{array}$ & $\mathrm{EuD}$ & $\begin{array}{l}\text { For the drying of moisture-stressed construction materials and the replacement of moisture- } \\
\text { damaged construction materials, their accessibility in the construction-typical assembled state is of } \\
\text { considerable relevance. In order to enable the rapid drying of moisture-stressed constructions, ex- } \\
\text { tensive and complex disassembly measures are required as appropriate, such as for example the } \\
\text { removal of various wall linings, dependent on the affected layer sequences. The same applies for the } \\
\text { replacement of moisture-damaged construction materials. The term disassembly capability contains } \\
\text { the simple, unambiguous and secure separation of multiple-part and/or multi-layer constructions in } \\
\text { this context. For disassembly-related structuring of component parts ("design for disassembly"), the } \\
\text { following apply as basic principles; (i) the minimisation of the employed materials, (ii) the reduc- } \\
\text { tion and unification of the jointing and connection locations, as well as (iii) the utilisation of simply } \\
\text { detachable connecting agents which are provided with functional capability over a defined effective } \\
\text { life. Two indicators are derived from these basic principles for the evaluation of the criterion: (i) a } \\
\text { directly measurable indicator, which considers the number of the employed construction materials } \\
\text { in the layer sequence and thus also the number of the joint and connection points, as well as (ii) a } \\
\text { qualitatively-describable indicator which establishes the connection between the type of the con- } \\
\text { necting agents and their detachability. }\end{array}$ \\
\hline $\begin{array}{l}\text { Microbial infesta- } \\
\text { tion and microbi- } \\
\text { ally-induced cor- } \\
\text { rosion (MIC) }\end{array}$ & $\mathrm{MiBe}$ & $\begin{array}{l}\text { The criterion includes the visible infestation of the component part surface and/or of the concealed } \\
\text { infestation of the component part interior by microorganisms (fungi, bacteria) as a result of a high- } \\
\text { water event. The microbial infestation can lead to a biogenic-stressing of affected component parts } \\
\text { that exceeds the background stressing usually present before the high-water event. The criterion is } \\
\text { used here for the evaluation of (i) the hazard of microbial growth, as well as (ii) the resistance capa- } \\
\text { bility of the component part and its components with respect to destruction through metabolic prod- } \\
\text { ucts of microorganisms. Among the significant growth-promoting factors for microorganisms are, } \\
\text { as well as the hygrothermal conditions, i.e. the temperature and the relative level of moisture on the } \\
\text { component part surface, a suitable ph-value as well as a bonded part and hydrophilic surface struc- } \\
\text { ture, particularly the existing nutrient concentration. The substrate quality therefore acts in this in- } \\
\text { vestigation as an indicator of the microbial infestation, i.e. of the spore sprouting and the visible } \\
\text { mycelium growth. }\end{array}$ \\
\hline $\begin{array}{l}\text { Electrolytic (met- } \\
\text { al) corrosion }\end{array}$ & Kor & $\begin{array}{l}\text { The criterion includes in this context the electrochemical oxygen corrosion of ferrous metals, which } \\
\text { can limit the duration of bonded component parts. Kaesche (2011) designates corrosion as the } \\
\text { measurable change starting from the surface, i.e. the detachment or conversion of metallic compo- } \\
\text { nent parts due to electrochemical reactions of the metal with component parts of the environment. } \\
\text { Prerequisites for the construction-related relevant oxygen corrosion in practice are (i) a diluted elec- } \\
\text { trolyte solution with dissolved air oxygen and (ii) that the metal oxidising pair has a lower oxida- } \\
\text { tion-reduction potential under standard conditions than the oxidising agent (here oxygen). The cor- } \\
\text { rosion process is always determined metal/electrolyte-related from the characteristics of the system. } \\
\text { Furthermore, the temperature and the ph-value are important for the corrosion process. The indica- } \\
\text { tor therefore measures the difference between the oxidation-reduction potential of the oxidising } \\
\text { agent and the metallic material. The potential difference correlates positively in a linear relationship } \\
\text { with the level of corrosion-promoting forces. }\end{array}$ \\
\hline
\end{tabular}

\subsection{Determining the weighting factors}

The stipulation of weighting coefficients serves to calculate the importance of every criterion with the evaluation of the damage susceptibility of construction alternatives. Weighting coefficients are accordingly ratio factors that characterise the relative importance of every individual criterion. Due to the number of evaluation criteria employed here $(n=11)$, the stipulation of the weighting coefficients is based on a pair-comparison method. This procedure allows the fragmentation of the problem and thus a more objective weighting appropriate to purpose. The AHP formalises the procedure, where criteria are systematically compared pairwise with each other.

Figure 5 includes the crosswise comparison of the weighted criteria. In direct comparison it is to be decided to what extent the first-designated criterion (horizontal) is to be considered as "more important" with regard to the evaluation question than the second designated criterion (vertical). The difference in importance is evaluated corresponding to Table 1 on a scale of 1 (equivalent) to 9 (maximum difference in importance).

The pairwise comparison evaluations are placed in the evaluation matrix $\boldsymbol{A}$. Then the column totals $S_{j}$ are calcu- 


\begin{tabular}{|c|c|c|c|c|c|c|c|c|c|c|c|}
\hline & DrFe & QzFe & $\mathrm{HzFe}$ & WaAuf & WaDu & DiSta & WL & TrVer & EuD & MiBe & Kor \\
\hline $\mathrm{DrFe}$ & 1.000 & 2.000 & 2.000 & 6.000 & 4.000 & 4.000 & 5.000 & 5.000 & 6.000 & 7.000 & 7.000 \\
\hline QzFe & 0.500 & 1.000 & 1.000 & 5.000 & 4.000 & 3.000 & 4.000 & 3.000 & 4.000 & 7.000 & 7.000 \\
\hline $\mathrm{HzFe}$ & 0.500 & 1.000 & 1.000 & 5.000 & 4.000 & 3.000 & 4.000 & 3.000 & 4.000 & 7.000 & 7.000 \\
\hline WaAuf & 0.167 & 0.200 & 0.200 & 1.000 & 1.000 & 2.000 & 1.000 & 1.000 & 2.000 & 4.000 & 4.000 \\
\hline WaDu & 0.250 & 0.250 & 0.250 & 1.000 & 1.000 & 0.333 & 1.000 & 1.000 & 3.000 & 3.000 & 3.000 \\
\hline DiSta & 0.250 & 0.333 & 0.333 & 0.500 & 3.000 & 1.000 & 3.000 & 3.000 & 3.000 & 5.000 & 5.000 \\
\hline WL & 0.200 & 0.250 & 0.250 & 1.000 & 1.000 & 0.333 & 1.000 & 1.000 & 1.000 & 3.000 & 3.000 \\
\hline TrVer & 0.200 & 0.333 & 0.333 & 1.000 & 1.000 & 0.333 & 1.000 & 1.000 & 1.000 & 6.000 & 6.000 \\
\hline EuD & 0.167 & 0.250 & 0.250 & 0.500 & 0.333 & 0.333 & 1.000 & 1.000 & 1.000 & 3.000 & 3.000 \\
\hline MiBe & 0.143 & 0.143 & 0.143 & 0.250 & 0.333 & 0.200 & 0.333 & 0.167 & 0.333 & 1.000 & 1.000 \\
\hline Kor & 1.000 & 2.000 & 2.000 & 6.000 & 4.000 & 4.000 & 5.000 & 5.000 & 6.000 & 7.000 & 1.000 \\
\hline \multicolumn{12}{|c|}{ Column sum } \\
\hline$S_{j}$ & 3.519 & 5.902 & 5.902 & 21.500 & 20.000 & 14.733 & 21.667 & 19.333 & 25.667 & 47.000 & 47.000 \\
\hline
\end{tabular}

Explanations

\begin{tabular}{|c|c|c|c|}
\hline DrFe ... & compressive strength & WL ... & thermal conductivity \\
\hline QzFe ... & $\begin{array}{l}\text { transverse tensile strength | } \\
\text { shear strength }\end{array}$ & TrVer ... & drying ability \\
\hline HzFe ... & $\begin{array}{l}\text { adhesive tensile strength | } \\
\text { adhesive shear strength }\end{array}$ & EuD ... & $\begin{array}{l}\text { accessibility and } \\
\text { design for disassembly }\end{array}$ \\
\hline WaDu ... & Leakage rate & MiBe ... & $\begin{array}{l}\text { microbial issues } \\
\text { mould grow }\end{array}$ \\
\hline $\begin{array}{l}\text { WAuf ... } \\
\text { DiSta ... }\end{array}$ & $\begin{array}{l}\text { water uptake } \\
\text { dimensional stability }\end{array}$ & Kor ... & corrosion \\
\hline
\end{tabular}

Figure 5. Evaluation matrix $\boldsymbol{A}$ (pairwise comparison matrix) representing the importance of each criterion relative to the other criteria.

lated and the elements of the matrix reset in order to determine the relative weighting values of the criteria. The result, i.e. the assignment of relative weighting values to the criteria, is included in the diagram in Figure 6. Obviously, the statics criteria are provided with the highest weighting coefficients. With the aid of the consistence index $C I$ and the consistence relationship $C R$, the consistence of the pair-comparison evaluation is checked.

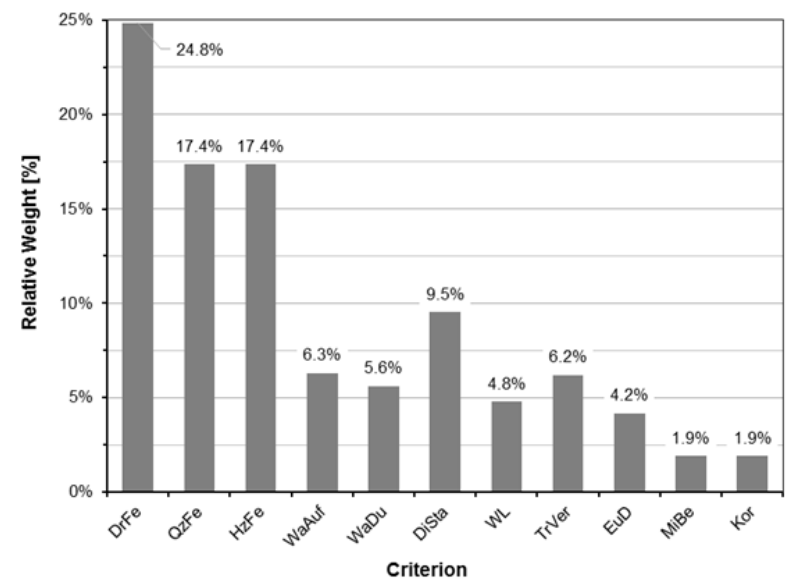

Figure 6. Relative weight [\%] of each criterion for the evaluation of the physical flood vulnerability of alternative masonry constructions.
The consistence index $C I$ is calculated with the aid of the equation

$$
C I=\frac{\bar{\lambda}-n}{n-1}=\frac{11,908-11}{11-1}=0,091
$$

The consistence relationship $C R$ corresponds to the equation:

$$
C R=\frac{C I}{R I}=\frac{0,091}{1,51}=0,060<0,100
$$

The consistence condition $C R<0.100$ is fulfilled so that no further verification of the consistence of the paircomparison evaluations is necessary.

\section{Results}

The results of the utility value process always refer to the layer sequences actually examined. They demonstrate the application of the evaluation methodology for the evaluation of the damage susceptibility. A transfer of the results to putatively similar construction design versions is linked with uncertainties since the evaluation results react sensitively to changes of the layer sequence.

Figure 8 indicates the total point value determined for every brickwork construction considered. The point values are interval-scaled, i.e. the doubling of the point value corresponds to a halving of the physical vulnerability. 
Included in the tendentially advantageous existing constructions with a point value greater than 0.5 , in accordance with Figure 8, is brickwork from

- traditional solid bricks (EMW-Mz),

- light-weight concrete hollow blocks with an external thermal insulation system (EMW-Hbl_WDVS) and

- calcareous sandstone with core insulation (ZMWKS_WZ).

A significant common characteristic of these three constructions is formed by the determined water impermeability within the experimental time period. This leads to a positive criterion evaluation and thus to a comparably high point value in the group of the building-physical criteria. Due to their favourable mechanical properties, also in case of increased water contents, these three layer sequences are furthermore provided with the highest point value in the most strongly weighted group of the static-constructive criteria (Figure 9).

\section{Conclusion}

In German and European legislation, the selfdependent high-water adaptation of potentially affected citizens forms an important pillar, whose objective is to effectively extend the governmental high-water precaution. For the application of this political objective the Federal Government, the States or the European Union with high probability will put in place grant programs which should support the implementation of concrete construction precautionary measures financially and thus should provide economic stimuli for action. In this case, the public materials handling providers would require however an operationalization instrument as mandatory for the evaluation of the effectiveness and cost efficiency of designed precautionary measures. This attachment can supply specialist stimuli for that.

Building on the experimental study for moisture behaviour, according to the second research question, specific methods and criteria for the determination and evaluation of the damage susceptibility of existing brickwork constructions are identified. In this case, the main focus

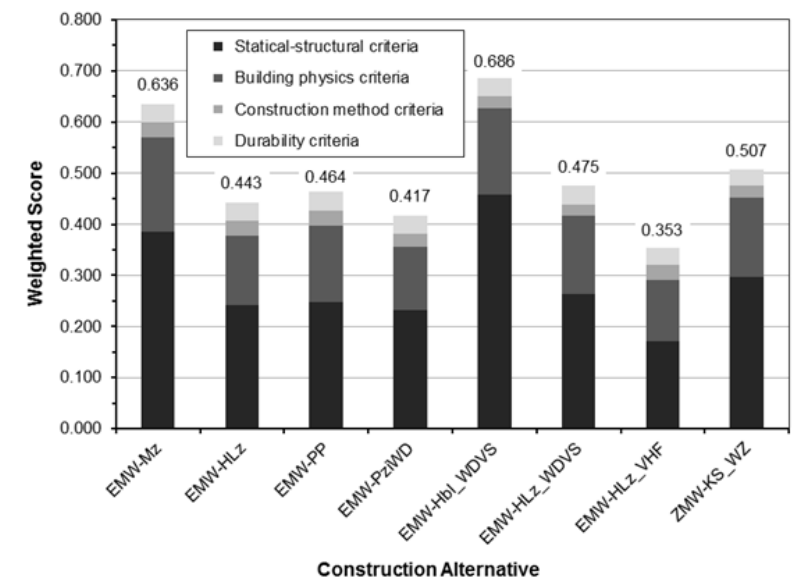

of the analysis of the interdependencies is primarily between the documented moisture behaviour and its disadvantageous results. The effect analyses serve for the development of relevant evaluation criteria and the selection of suitable indicators.

A process which supports the systematic evaluation of construction alternatives by means of different quantitative criteria is the utility value analysis. The evaluation procedure is based on a hierarchical target system which includes eleven criteria, as well as the corresponding objective functions and partial weight. The higher a key indicator determined with the utility value method, the lower the damage susceptibility of the construction with respect to high-water influences is estimated.

Each of the eleven evaluation criteria is to be assigned to one of four groups. The first group of the staticconstructive criteria includes the compressive strength, transverse tensile strength and adhesion tensile strength of the external wall components. The water absorption characteristics, the water permeability, the dimensional stability and the thermal conductivity, as well as the drying characteristics, are associated with the second group of the building-physical criteria. A third group contains criteria of construction design, nevertheless in this study only the disassembly capability, i.e. the simple and secure separation of multiple-part and multi-layer constructions, is considered. Criteria of permanence form the fourth group. The evaluation of microbially-induced and electrolytic corrosion processes is linked into that.

In order to enable the assessment of the influence of each of these criteria on the damage susceptibility of the brickwork construction, criteria-related objective functions were developed. These objective functions evaluate the deviations of the value occurrences (actual values) determined from certain target values (setpoint values). The stipulation of the target values is based on the generally recognised regulations of the technology, as well as on specialist standards from technical regulatory works and directives. In addition, the integration of already available research results of the engineering sciences guarantees the general legitimacy and relevance in prac-

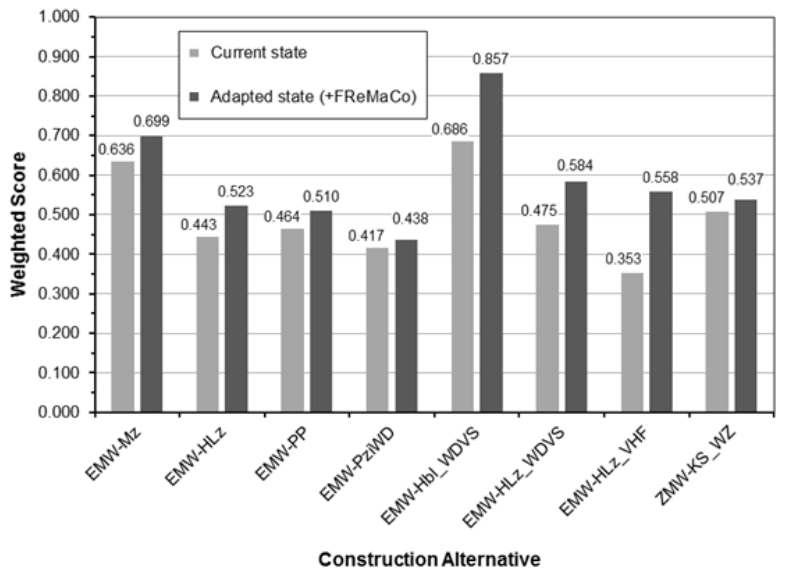

Figure 7. Left chart: Weighted score for each construction alternative. Right chart: Weighted score for each construction alternative in the current state, i.e. without any adaptations, and in the adapted state, i.e. including FReMaCo. 
tice of the target values employed. The majority of construction materials in a jointed construction change their characteristic values depending on the water content. The larger the differences determined between the target values and the changed characteristic values, the more marked the disadvantageous results of the hygrographic stressing.

The determination of the partial weighting values, which, as scale factors, calculate the importance of every individual criterion in the evaluation procedure, is based on the pair-comparison method of the analyticalhierarchical process.

This work describes a methodology, which for the first time operationalises the evaluation of the damage susceptibility of alternative standard cross-sections with respect to high-water influences. In this way, a transparent and understandable differentiation is achieved between disadvantageous and advantageous construction design solutions. On the basis of this evaluation, construction alternatives are transferable in an order of priority with regard to their damage susceptibility.

An important field of application of the results is, on the one hand, the development and, on the other hand, the promotion of structural-engineering measures of the highwater precautions. The development of specific adaptation measures is based on the evaluation results acquired which identify the decisive deficits of the actual status and thus support the more purposeful derivation of solutions. The promotion of concrete adaptation measures is a political objective. For the application of this political objective, the federal states, the German Federal Government or the European Union will with high probability put in place grant programs, which financially support the implementation of construction precautionary measures, and thus amplify stimuli for action. An operationalization instrument is available to the public materials handling provider with this work for the evaluation of both the damage susceptibility of existing constructions and the effectiveness of designed adaptation measures.

\section{References}

Blanco A. and Schanze J. (2014). Assessment of the physical flood susceptibility of buildings on a large scale - conceptual and methodological frameworks. Natural Hazards and Earth System Sciences, 14(8), 2105-2117.

Bowker P., Escarameia M. and Tagg A. (2007). Improving the flood performance of new buildings - Flood resilient construction. London: RIBA Publishing.

Connelly A., Gabalda V., Garvin S., Hunter K., Kelly D., Lawson N., O'Hare P. and White I. (2015). Testing innovative technologies to manage flood risk. Proceedings of the Institution of Civil Engineers - Water Management, 168(2), 66-73.

Douglas I., Garvin S., Lawson N., Richards J., Tippet J. and White I. (2010). Urban pluvial flooding: a quantitative case study of cause, effect and non-structural mitigation. Journal of Flood Risk Management, 3(2), 112-125.
Escarameia M., Karanxha A. and Tagg A. (2007). Quantifying the flood resilience properties of walls in typical UK dwellings. Building Services Engineering Research and Technology, 28(3), 249-263.

Escarameia M., Tagg A., Walliman N., Zevenbergen C. and Anvarifar F. (2012). The Role of Building Materials in Improved Flood Resilience and Routes for Implementation. In: F. Klijn and T. Schweckendiek (Eds.) Comprehensive Flood Risk Management: Research for Policy and Practice. Proceedings of the 2nd European Conference on Flood Risk Management FLOODrisk2012. Rotterdam, The Netherlands, 19-23 November 2012. Boca Raton: CRC Press, 333-335.

European Union (2007). Directive 2007/60/EC of the European Parliament and of the Council of 23 October 2007 on the assessment and management of flood risks [online].

Available from: http://eur-

lex.europa.eu/LexUriServ/LexUriServ.do?uri1/4OJ:L:2007:288:0 027:0034:EN:PDF

[Accessed 26 February 2016].

FEMA (2010). Protecting your home and property from flood damage - Mitigation ideas for reducing flood loss. Washington, DC: FEMA - Federal Emergency Management Agency.

Gamerith H. and Hoefler K. (2006). Praeventiver Hochwasserschutz - Planungsgrundsaetze [Preventive flood protection Planning Principles]. Graz: ARGE.

Garvin S. (2012). Flood Resilient Building - Part 2: Building in flood-risk areas and designing flood-resilient buildings. Watford: BRE Press.

Gabalda V., Garvin S., Hunter K., Florence C., Salagnac JL., Golz S., Veldhuis M-C., Diez J. and Monnot JV. (2012). Flood resilience technologies. Deliverable 2.3 of the EU-FP7 research project 'Smart Resilient Technology, Systems and Tools' (SMARTeST) [online]. Available from: http://www.floodresilience.eu/attachments/article/165/D2.3\%20 final-July13.pdf

[Accessed 20 September 2014].

Golz S. (forthcoming). Bewertung der Schadensanfälligkeit von Mauerwerkskonstruktionen gegenüber Hochwassereinwirkungen. [Assessing the flood vulnerability of external wall constructions.] Dissertation. Technische Universität Dresden.

Golz S., Schinke R. and Naumann T. (2015). Assessing the effects of flood resilience technologies on building scale. Urban Water Journal, 12(1), 30-43.

Lawson N. (2011). The Flood Risk Management Glossary. Incorporating FLOODsite Glossary (FLOODsite), Flood Mapping Manual Editorial Group Glossary (FMMEP), Urban Flood Management Glossary (UFM), and the SMARTeST Project Glossary (SMARTeST). Manchester: The University of Manchester.

Merz B., Kreibich H., Schwarze R. and Thieken A. (2010). Assessment of economic flood damage.Natural Hazards and Earth System Sciences, 10, 1697-1724.

Naumann T., Nikolowski J. and Golz, S. (2009). Synthetic depth-damage functions - a detailed tool for analysing flood resilience of building types. In: E. Pasche, N. Evelpidou, C. Zevenbergen, R. Ashley and S.L. Garvin (Eds.) Road Map Towards a Flood Resilient Urban Environment. Hamburg: 
Institut fuer Wasserbau der Technischen Universität HamburgHarburg.

Naumann T., Nikolowski J., Golz S. and Schinke R. (2010). Resilience and Resistance of Buildings and Built Structures to Flood Impacts - Approaches to Analysis and Evaluation. In: B. Mueller (Ed.) German Annual of Spatial Research and Policy 2010 - Urban Regional Resilience: How Do Cities and Regions Deal with Change? Berlin, Heidelberg: Springer Verlag, 89100.

OECD (2002). Evaluation and aid effectiveness - Glossary of key terms in evaluation and results based management. Paris; Organisation for Economic Co-operation and Development (OECD), Development Assistance Committee (DAC) [online]. Available from: http://www.oecd.org/ dataoecd/29/21/2754804.pdf

Samuels P. and Gouldby B. (2009). Language of Risk Project Definitions. 2nd edition, FLOODsite Consortium, FLOODsite Project Report T32-04-01 [online].

Available from:

http://www.floodsite.net/html/partner_area/project_docs/floodsi te language_of_risk_v4_0_p1.pdf

[Accessed 20 September 2014].

USACE (1998). Flood Proofing Performance - Success and Failures. Washington, DC: U.S. Army Corps of Engineers National Flood Proofing Committee.

White I. (2010). Water and the City: Risk, resilience and planning for a sustainable future. London: Routledge.

White I., Connelly A, Lawson N. and O' Hare P. (2013). Integration of Flood Resilience Technologies, Systems and Tools. Deliverable 5.3 of the EU-FP7 research project 'Smart Resilient Technology, Systems and Tools' (SMARTeST) [online].

Available from:

http://www.floodresilience.eu/attachments/article/171/D5.3\%20

final-July $13 \% 5 \mathrm{~B} 1 \% 5 \mathrm{D}$.pdf

[Accessed 20 September 2014]. 